\title{
Uma abordagem utilizando comunidades de prática para o aprendizado de alunos com baixa visão na modalidade de ensino a distância
}

Tatiana Takimoto, UFSC/EGC, tatiana@egc.ufsc.br Gertrudes Aparecida Dandolini, UFSC/EGC, ggtude@gmail.com João Artur Souza, UFSC/EGC, jartur@gmail.com Tarcísio Vanzin, UFSC/EGC, vanzin@egc.ufsc.br

Resumo. O Programa de Pós Graduação em Engenharia e Gestão do Conhecimento, da Universidade Federal de Santa Catarina, com apoio do PROESP CAPES, possui um projeto - WebGD - cujo foco é o desenvolvimento de um ambiente web adaptável e acessível para o ensino da disciplina Geometria Descritiva. Este artigo apresenta parâmetros necessários para a inclusão social e educacional do aluno com baixa visão e se baseia na estratégia das comunidades de prática para motivar a participação e a interação entre os alunos. Realiza-se uma revisão de literatura sobre educação a distância, cognição situada e comunidades de prática, conceitos que fundamentam o projeto WebGD, e uma revisão de literatura sobre baixa visão. Apresentam-se ao final os requisitos necessários para o desenvolvimento das próximas etapas do projeto WebGD.

Palavras-chave: comunidades de prática, tecnologias de informação e comunicação, educação a distância, baixa visão

Abstract. The Graduate Program in Engineering and Knowledge Management, at Federal University of Santa Catarina, with support from CAPES PROESP, has a project - WebGD - whose focus is the development of an adaptable and accessible web environment for teaching the discipline Descriptive Geometry. This article presents the parameters needed for social and educational inclusion of students with low vision and it is based on strategy to encourage participation and interaction on communities of practice. It held a review of literature on distance education, situated cognition and communities of practice, concepts that support the project WebGD, and a literature review of low vision. Presents at the end requirements needed to develop the next stages of the project WebGD.

Keywords: communities of practice, information and communication technologies, distance education, low vision.

\section{Introdução}

O crescimento da internet e a evolução das tecnologias de informação e comunicação contribuíram para um aumento considerável dos cursos de Educação à Distância, em 
função da quebra da barreira de tempo e espaço, superando problemas de distância física e disponibilidade de tempo. Segundo dados do INEP de 2008, 115 instituições ofereceram 647 cursos à distância no Brasil. As matrículas na modalidade de ensino a distância aumentaram 96,9\% em relação ao ano anterior e, em 2008, passaram a representar $14,3 \%$ do total de matrículas no ensino superior. Além disso, o número de concluintes em educação a distância cresceu 135\% em 2008, comparado a 2007. Entretanto não está disponível a informação de quantos alunos concluintes apresentam alguma deficiência seja ela visual, auditiva ou motora. A inclusão social e educacional de alunos com deficiência demanda a realização de projetos e pesquisas que a torne viável e efetiva, afirmam Melo et al (2004).

O Programa de Pós Graduação em Engenharia e Gestão do Conhecimento, da Universidade Federal de Santa Catarina, com apoio do PROESP CAPES, possui um projeto cujo foco é o desenvolvimento de um ambiente web adaptável e acessível para o ensino da disciplina Geometria Descritiva na ótica da educação inclusiva. A proposta deste artigo consiste em identificar as necessidades do usuário com baixa visão, dentro dos parâmetros preconizados pelos autores Kulpa et al (2010), Pereira e Costa (2009), Mendonça et al (2008), Bonatti (2006) e Rocha e Baranauskas (2003), confrontando-as com as diretrizes das comunidades de prática, proposta por Wenger (1998). O levantamento desses requisitos são necessários para a continuidade do projeto WebGD incluindo o aluno de baixa visão.

Realiza-se a revisão bibliográfica sobre educação a distância, cognição situada e comunidades de prática, pois estes conceitos fundamentam e apóiam a proposta do projeto WebGD. As dificuldades dos alunos com baixa visão aqui relatadas, servirão de base para a continuidade do projeto WebGD e facilitarão a elaboração de estratégias de inclusão destes alunos nas disciplinas de educação a distância, proporcionando a eles um conforto que favoreça a sua interação com o restante da classe e consequentemente o seu aprendizado.

\section{Projeto WebGD}

O objetivo do projeto WebGD é desenvolver um ambiente web adaptável e acessível para o ensino da disciplina Geometria Descritiva na ótica da educação inclusiva. $\mathrm{O}$ material didático será implementado no ambiente virtual de aprendizagem Moodle, por seu princípio pedagógico estar voltado ao "construtivismo social", abrangência e alta interatividade. O público que irá cursar esta disciplina será o de alunos jovens sem deficiência e com deficiência auditiva e/ou visual, cursando nível superior ou técnico, das áreas de Engenharia, Matemática, Design, Artes ou outra área que tenha esta disciplina ou uma disciplina equivalente no seu currículo.

A disciplina Geometria Descritiva tem como meta aprimorar a visão espacial desses alunos, ensinando-os a representar um objeto de três dimensões em um plano bidimensional. Um dos resultados obtidos deste projeto é a tese de doutorado de Macedo (2010) que versa sobre diretrizes para criação de objetos de aprendizagem acessíveis. Esta tese apoiará a criação dos objetos de aprendizagem adaptáveis e acessíveis que serão disponibilizados no AVA do projeto. A dissertação de Kaminski (2008), sobre a inserção das diretrizes de acessibilidade em um Sistema Hipermídia Adaptativo, forneceu informações para o desenvolvimento da interface gráfica abaixo:

V. $9 \mathrm{~N}^{\mathrm{o}} 1$, julho, 2011 


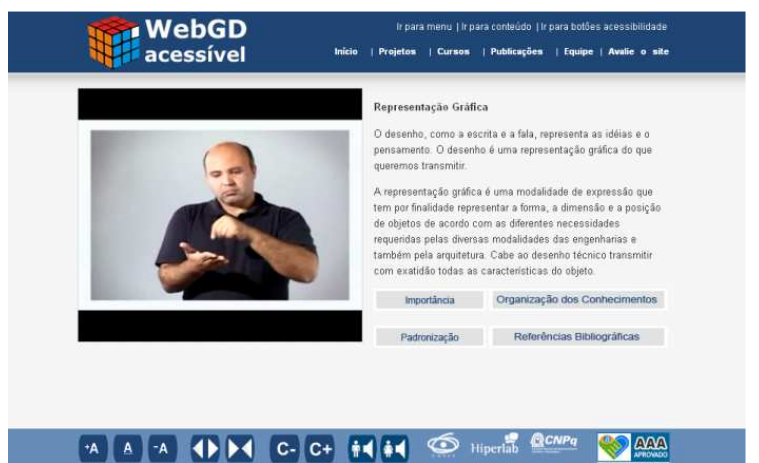

Figura 1 - Página principal do website WebGD

Alguns cuidados já foram tomados no desenvolvimento desta interface: A programação do website está de acordo com as recomendações da World Wide Web Consortion (W3C) e com as diretrizes de acessibilidade ao conteúdo da Web (WCAG), de modo que a interface já está acessível para usuários cegos e surdos (AMARAL ET AL., 2011). O projeto está ainda em sua fase inicial e, para dar prosseguimento, se investiga neste artigo as necessidades do aluno com baixa visão. As recomendações encontradas em Mendonça et al (2008) e Kulpa et al (2010) para alunos com baixa visão são apresentadas a seguir:

1) Evitar fontes cursivas, decorativas, itálicos e com serifas;

2) Usar fontes em que todas as letras ocupem um espaço de dimensão fixa ou aquelas em que o espaço é proporcional à letra;

3) Usar o tipo bold mas nunca o extra-bold e evitar sublinhados;

4) Justificar apenas a margem esquerda do texto;

5) Nas imagens eliminar os detalhes desnecessários;

6) O conteúdo da página deve conter o mínimo possível de informações;

7) O conteúdo da interface deve estar organizado em uma coluna bem definida;

8) Indicação do menu principal de forma destacada em alto contraste;

9) O menu principal deve estar à esquerda da página;

10) Ampliação da tela sem diminuição da qualidade;

11) A interface não deve conter imagens em movimento;

12) O espaço deve ser maior nas "entre-letras" quando ampliadas;

13) A cor do fundo deve mudar sempre que o cursor passar por um link;

14) Utilizar alto contraste entre o fundo e o texto;

15) Utilizar poucas cores em uma mesma página.

Kulpa et al (2010) apresentam nove opções de cores testadas entre usuários com baixa visão. Os autores afirmam que, ao contrário do que vários colaboradores acreditavam, o contraste do fundo preto com letras amarelas não trouxe benefícios aparentes para a leitura e entendimento da interface para a maioria dos usuários. $\mathrm{O}$ fundo azul escuro com letra branca, amarelo luminoso, azul claro ou laranja claro foi o contraste que permitiu o melhor desempenho na navegação da interface e se mostrou ser o mais eficiente para leitura. $\mathrm{O}$ fundo preto com letra branca, azul claro, amarelo 
luminoso ou verde luminoso alcançou diversos tipos de diagnósticos de baixa visão. Outras combinações de cores são recomendadas pelos autores para o auxílio na identificação de ícones, tópicos e títulos. Kulpa et al (2010) também apresentam combinações de contrastes para usuários com e sem sensibilidade à luz. Os estudos de Kulpa et al (2010) servirão de base para as implementações a serem feitas na interface do projeto WebGD.

Para facilitar o aprendizado dos alunos, o projeto WebGD toma como princípio a teoria da cognição situada que versa sobre aprendizado colaborativo e social, onde a interatividade é parte integrante do processo educacional. Segundo Palloff e Pratt (2007), a chave para o processo de aprendizado é a interação entre os alunos, a interação entre alunos, professores e tutores e a colaboração resultante desta interação. Para Lave (2003) citada por Vanzin (2005), a aprendizagem situada se apóia em dois princípios:

1) $\mathrm{O}$ conhecimento precisa ser apresentado e aprendido em um contexto autêntico, ou seja, com os elementos e aplicações que naturalmente envolveriam esse conhecimento.

2) Aprendizagem requer interação social e colaboração.

Em função desses dois princípios, a disciplina Geometria Descritiva prevê a contextualização dos alunos, que permitirá a eles aplicar o que foi aprendido. Segundo Vanzin (2005) "as atividades cognitivas resultantes dos processos de aprendizagem só podem ser explanadas quando relacionadas ao contexto". Para isso é preciso que os educadores conheçam seus alunos e o contexto da sua vida social, mesmo que na educação a distância. Neste sentido, Palloff e Pratt (2007) afirmam que para mediar o aprendizado online, os educadores precisam conhecer as necessidades dos alunos. No caso específico do projeto WebGD, este conhecimento se dá através de estudos e pesquisas bibliográficas, bem como pesquisas qualitativas, face-a-face com pessoas que apresentam dificuldades visuais e auditivas. Essas pesquisas fornecem uma base de informações que permitirão adequar a interface gráfica digital do ambiente virtual de aprendizagem e os objetos de aprendizagem que nele serão disponibilizados.

\section{Educação a Distância}

A educação a distância (EaD), para Keegan (1996, p.6), é uma modalidade de ensino e aprendizagem na qual professores e alunos ficam separados geograficamente. Segundo Oliveira (2006, p.34), o estudante de EaD tem autonomia para realizar buscas aos conteúdos que lhe interessam, assumindo uma postura ativa e responsável frente ao seu aprendizado. A conjunção da autonomia com a facilidade dos estudantes em encontrar informações e consequentemente produzir conhecimento, faz com que os professores desta modalidade alterem sua conduta. Neste cenário é possível afirmar que dentre as mudanças ocorridas na educação a distância durante os séculos XX e XXI, a mais revolucionária está no campo da comunicação através da mídia internet.

Segundo Belloni (2008), as mesmas tecnologias de informação e comunicação (TIC) que intensificam o processo de globalização são utilizadas pela EaD. Desta forma as TICs se tornaram fundamentais no processo de ensino e aprendizagem a distância, deixando de ser uma opção e se tornando uma característica desta modalidade. A EaD deve, portanto, adequar-se às novas tecnologias e inseri-las no dia-a-dia da educação, explorando recursos como hipermídia e redes de comunicação interativa.

V. $9 \mathrm{~N}^{\mathrm{o}} 1$, julho, 2011 
A comunicação na modalidade EaD ocorre entre alunos, tutores e professores, em ambientes virtuais de aprendizagem, que de modo geral procuram características semelhantes às da sala de aula, com interesse especial na interatividade. $\mathrm{O}$ acesso a arquivos de conteúdos relacionados com o tema é altamente facilitado e a sensação de isolamento, característica das antigas formas de $\mathrm{EaD}$, não existem mais em função das indicações de presença dos demais membros do grupo, dos softwares de comunicação rápida e dos recursos de comunicação com voz e imagem online.

\section{Ambiente Virtual de Aprendizagem}

O conceito de ambiente virtual de aprendizagem (AVA) consiste em uma "opção de mídia que está sendo utilizada para mediar o processo ensino-aprendizagem a distância", afirmam Pereira et al (2007, p.5). Lima (2006, p.24) acrescenta que a utilização de AVAs está aumentando no meio acadêmico, tanto em instituições de ensino privadas como públicas e também em organizações ligadas de alguma forma ao ensino. O Moodle (Modular Object-Oriented Dynamic Learning Environment), software livre desenvolvido pelo australiano Martin Dougiamas, é um exemplo de AVA que está sendo utilizado por 54.442 sites registrados em 212 países. No Brasil 3.863 instituições utilizam o Moodle, é o que afirma a estatística presente no site da comunidade Moodle (MOODLE, 2011). Este número indica a necessidade de estudos na área para que os AVAs sejam efetivos no seu objetivo, que é o de proporcionar um ambiente gestor de recursos que agilize a disponibilização e troca de arquivos e que facilite a integração entre os participantes, tudo de forma a favorecer o aprendizado.

Embora o avanço das TICs possibilite o surgimento de novas formas de comunicação, interação e colaboração, Lima (2006, p.25) alerta para o fato de que os AVAs muitas vezes são utilizados como meros repositórios e ferramentas de distribuição de materiais instrutivos, acabando por não utilizar todo o potencial que as TICs oferecem. Kenski (2007, p.45) corrobora Lima (2006, p.25) ao afirmar que mesmo a televisão e o computador, considerados tecnologias comunicativas mais utilizadas em educação, ainda não provocaram alterações radicais na estrutura dos cursos.

A mudança de comportamento dos envolvidos no processo de ensino e aprendizagem está sendo discutida sob vários aspectos. Wenger (1999, p.267) afirma que os debates pedagógicos são realizados com foco em opções como autoridade versus liberdade, instrução versus descobrimento, individual versus coletivo. O autor ressalta que todos esses debates direcionam para a questão interatividade e sugere que os AVAs devem priorizar o aprendizado coletivo, utilizando as TICs para colaboração e cooperação entre os alunos, tutores e professores.

Estudos de Palloff e Pratt (2008, p. 42) sobre educação online indicam que o aluno matriculado em $\mathrm{EaD}$, especialmente os jovens, têm uma facilidade maior com as TICs quando comparados aos próprios professores. Esses alunos costumam utilizar as tecnologias de comunicação para participar de redes sociais. Neste contexto, os autores afirmam que os professores devem incentivar o senso de comunidade entre os estudantes, o que remete ao conceito de comunidades de prática, cunhado pelo pesquisador Etienne Wenger (1998).

\section{Comunidades de Prática}

V. $9 \mathrm{~N}^{\mathrm{o}} 1$, julho, 2011 
Os autores Jean Lave e Etienne Wenger (1991) foram pioneiros na formulação da teoria da cognição situada cujo foco é a relação entre o aprendizado e a situação social onde ele ocorre (1991, p.14). Segundo os pesquisadores, a aprendizagem é uma dimensão social, adquirida pela experiência, pela participação e pela colaboração na vida cotidiana. Para Palloff e Pratt (2007), o aspecto social do aprendizado é o fator mais importante na aquisição do conhecimento. Como conseqüência desta afirmação o conceito de comunidade de prática ganha importância, na medida em que seus membros desenvolvem um sentimento de confiança e passam a compartilhar informações e experiências.

O termo comunidade de prática (CoP) foi cunhado por Wenger (1998) para denominar grupos de pessoas que interagem, aprendem juntos, constroem relacionamentos pessoais e desenvolvem um senso de pertencimento e compromisso mútuo. Ao ingressar no ambiente online, as comunidades de prática passam a ser consideradas, de acordo com Terra e Gordon (2002, p.77), comunidades virtuais. Segundo os autores, o ambiente virtual da comunidade de prática serve como uma plataforma de hipermídia para troca e armazenamento de arquivos, sejam eles imagens, sons, vídeos ou textos. Além disso, com o forte potencial de comunicação da internet, essas comunidades ultrapassam as barreiras de países, faixa etária e organizações com fins lucrativos ou não, resultando em uma participação bastante ampla. Mais do que encontros virtuais, uma comunidade virtual preza pela geração e troca de idéias, em uma abordagem de apoio aos seus membros, tendo como resultado uma colaboração mútua e efetiva.

Pesquisas de Palloff e Pratt (2007) apontam uma crescente valorização das comunidades em AVAs. Os resultados destas pesquisas oferecem suporte para o entendimento de que a chave para o sucesso do aprendizado online é a formação de efetivas comunidades virtuais. Adams e Sperling (2003) citados por Palloff e Pratt (2007) descrevem algumas mudanças positivas como, por exemplo, um maior acesso às informações e um maior envolvimento dos professores e dos estudantes, com aumento da responsabilidade tanto em ensinar como em aprender. Desta forma é possível afirmar que o sucesso do aprendizado online depende mais da metodologia adotada do que do AVA ou das TICs. Tal metodologia deve incentivar a interatividade e a participação entre os atores do processo. Os alunos precisam contribuir para o aprendizado coletivo, expressando suas idéias nas discussões online. Assim alunos e professores participarão do processo de aquisição do conhecimento colaborativamente (PALLOFF e PRATT, 2007).

Takimoto et al. (2010) apresentam uma proposta de metodologia para EaD baseada nos estudos sobre como encorajar a participação em uma comunidade de prática realizados por McKenzie-Mohr e Smith (1999) e Chan et al. (2004). A proposta de Takimoto et al. (2010) envolve:

Etapa 1: identificação das barreiras à participação;

Etapa 2: identificação dos incentivos à participação;

Etapa 3: Desenvolvimento de uma estratégia de participação considerando o comportamento social e cultural do grupo, as dificuldades à participação, os fatores motivadores do envolvimento, a participação de minorias e a criação de incentivos e recompensas.

V. $9 \mathrm{~N}^{\mathrm{o}}$ 1, julho, 2011 
Etapa 4: Execução da estratégia de participação.

Etapa 5: Avaliação da estratégia de participação adotada, para obter insights e conhecimento sobre todo o processo. Ao final desta etapa retorna-se ao ponto de partida corrigindo as falhas encontradas durante a avaliação.

A metodologia apresentada sugere uma mudança comportamental dos educadores. É preciso que eles ouçam o que não foi dito conforme comentam Monteiro et al (2010) sobre o estudo de um fórum virtual utilizado em práticas educativas. Segundo os autores, existe uma necessidade de uma "escuta mais atenta" por parte dos educadores, no sentido de identificar as dificuldades que impedem uma real interação.

Essas dificuldades se agravam quando existem alunos com algum grau de deficiência seja ela auditiva, motora ou visual. Neste caso professores e tutores deverão desempenhar uma atenção especial ao item "participação de minorias", citado na etapa 3 da metodologia de Takimoto et al (2010).

\section{Deficiente de baixa visão}

Segundo Bonatti (2006), em 1992, a Organização Mundial de Saúde (OMS) definiu uma pessoa com baixa visão como aquela "que tem prejuízo visual mesmo depois do tratamento e/ou correção refrativa habitual”. Esta pessoa, entretanto, consegue utilizar a visão para executar ou planejar tarefas.

De acordo com Vanderheinde \& Vanderheiden (1991) citados por Kulpa et al. (2010) o deficiente de baixa visão possui problemas como: escurecimento da visão; visão embaçada, névoa, película nos olhos; visão apenas de objetos extremamente próximos; perda de visão à distância; visão distorcida; manchas na frente da visão; distorção das cores ou daltonismo; defeitos no campo visual; visão em túnel; falta de visão periférica; sensibilidade anormal à luz ou à claridade; cegueira noturna.

Além dos dados citados, o Programa de capacitação de recursos humanos do ensino fundamental (BRASIL, 2001, p.64) aponta para o fato de que cada aluno de baixa visão é único e cada um pode apresentar uma dificuldade diferente do outro. Enquanto para alguns alunos é necessário o uso da alta iluminação, para outros a luminosidade e brilho podem dificultar ainda mais a fixação e a discriminação visual. Sendo assim, o papel dos educadores é objetivar o enriquecimento do conhecimento eliminando tais barreiras visuais significativas. A padronização neste caso não é aconselhável, visto que os elementos da interface gráfica do AVA devem se adaptar às necessidades de cada aluno.

Alguns alunos apresentam dificuldades visuais crescentes, que muitas vezes os levam a aguçar sentidos como o tato e a audição. Neste cenário os autores Mendonça et al (2008) consideram de fundamental importância o uso das TICs para o desenvolvimento social e profissional desses alunos. As TICs, aliadas a uma pedagogia adequada que visa a integração social do estudante, permitirão ao aluno de baixa visão utilizar o tato, a audição e os resíduos visuais de forma eficiente em todas as atividades, garantindo a organização do seu conhecimento e um maior grau de liberdade e autonomia.

A política de integração social, conceito básico das comunidades de prática, facilita a quebra do preconceito social, considerado uma das barreiras mais significativas do deficiente de baixa visão, afirmam Pereira e Costa (2009). Os 
educadores devem, portanto, desenvolver sua estratégia de participação, considerando o comportamento social do grupo e do aluno de baixa visão. Além disso, professores e tutores devem eliminar as barreiras à participação e promover incentivos à interação e colaboração, incluindo o aluno deficiente.

Nessa perspectiva, o projeto em desenvolvimento - WebGD, com apoio do PROESP CAPES, faz uso da metodologia de Takimoto et al (2010) e se apóia nas teorias da Cognição Situada e das Comunidades de Prática.

\section{Considerações finais}

Embora os avanços na informática apontem para uma crescente demanda dos cursos de $\mathrm{EaD}$, as TICs não são utilizadas de modo efetivo nesta modalidade, especialmente as que proporcionam a interatividade. Faz-se necessário uma mudança de metodologia que proporcione o convívio social entre os alunos e com isso torne possível a troca de experiências, informações e conhecimento entre eles. Para motivar a participação e garantir o aprendizado dos alunos, sejam eles deficientes ou não, o projeto WebGD se estrutura nos conceitos da cognição situada (LAVE e WENGER,1991) e comunidades de prática (Wenger, 1998).

Este artigo apresenta o uso de uma metodologia (TAKIMOTO ET AL, 2010), baseada nas estratégias de motivação das comunidades de prática, que está sendo empregada no desenvolvimento do projeto WebGD. Uma das etapas da metodologia prevê a inclusão de minorias, aqui representadas pelos alunos de baixa visão. Como uma das etapas da metodologia de Takimoto et al (2010) prevê a eliminação das barreiras à participação, fez-se necessário o estudo do público de baixa visão. Este artigo apresentou uma síntese das barreiras enfrentadas por estes alunos e algumas soluções gráficas para eliminá-las.

Próximas etapas deste projeto incluem a implementação e adequação da interface com os requisitos aqui reunidos, testes da interface com pessoas de baixa visão, criação de objetos de aprendizagem acessíveis para os 12 módulos previstos da disciplina e desenvolvimento de um ambiente virtual colaborativo para troca de informações, conhecimento e experiência entre alunos e professores. Acredita-se que a abordagem interdisciplinar presente no desenvolvimento do projeto WebGD seja favorável ao bom rendimento e aprendizado dos alunos e também dos educadores.

\section{REFERÊNCIAS}

AMARAL .A.M; CECÍLIO, R.; ULBRICHT V.R.; BERG, C.H.; DANDOLINI, G.; KAMINSKI, D. Websites Acessíveis e o uso de CMS. In: VI CONGRESSO IBEROAMERICANO DE TELEMÁTICA, 6, 1, 2011, Gramado. Anais. Gramado: CITA. p. 187-194.

BELLONI, M.L. Educação a distância. Campinas, SP: Autores Associados, 2008. $124 p$.

BONATTI, F.A.S. Desenvolvimento de equipamento de auxílio à visão subnormal. Arquivos Brasileiros de Oftalmologia, v.69, n.2,p.221-226, 2006. 
BRASIL. Programa de Capacitação de Recursos Humanos do Ensino Fundamental: deficiência visual. Brasília: Ministério da Educação, Secretaria de Educação Especial, 2001. v.2.

KEEGAN, D. Foundations of distance education. New York: RoutledgeFalmer, 1996. $240 \mathrm{p}$.

KENSKI, V.M. Educação e Tecnologias: o novo ritmo da informação. Campinas, SP: Papirus, 2007.

KULPA, C.C; TEIXEIRA, F.G, SILVA, R.P. Um modelo de cores na usabilidade das interfaces computacionais para $\mathrm{s}$ deficientes de baixa visão. Design \& Tecnologia Revista do programa de pós-graduação em Design da UFRGS, Porto Alegre: v.1, n.1., p.66-78, 2010

LAVE, J. Cognition in Practice: Mind, mathematics and culture in everyday life. New York. Cambridge University Press, 1988. 214 p.

LAVE, J., WENGER, E. Situated Learning: Legitimate Peripheral Participation. Cambridge: Cambridge University Press, 1991. 138 p.

LIMA, P.S.R. Um Ambiente Colaborativo de Aprendizagem Interdisciplinar Apoiado por Interfaces Adaptativas, no Estado do Pará, Belém: UFPA / CT / PPGEE, 2007. 259 p. Tese de Doutorado.

MACEDO, C.M.S. Diretrizes para criação de objetos de aprendizagem acessíveis, no Estado de Santa Catarina. Florianópolis: UFSC/EGC, 2010, 271 p. Tese de Doutorado.

MELO, A.M., BARANAUSKAS, M.C.C., BONILHA, F.F.G. Avaliação de acessibilidade na Web com a participação do usuário: um estudo de caso. In: SIMPÓSIO SOBRE FATORES HUMANOS EM SISTEMAS COMPUTACIONAIS, 6., 2004, Curitiba, Anais do VI Simpósio sobre Fatores Humanos em Sistema, 2004. SBC. Porto Alegre, RS. pp. 165-168

MENDONÇA, A.; MIGUEL C.; NEVES G.; MICAELO, M.; REINO, V. Alunos cegos e com baixa visão: orientações curriculares. Lisboa: Direcção-Geral de Inovação e de Desenvolvimento Curricular, 2008. 87 p.

MONTEIRO, D.M.; RIBEIRO, V.M.B.; STRUCHINER, M. As tecnologias da informação e da comunicação nas práticas educativas: espaços de interação? Estudo de um fórum virtual. Educação e Sociedade - Revista de ciência da educação, Campinas, v.28, n.101, p 1435 - 1454, set./dez. 2007. 
MOODLE. Software livre. Desenvolvido por 279 programadores. Apresenta aplicativos para educadores usarem na criação de sites de aprendizado. Disponível em: http://moodle.org/sites/. Acesso em: 27 maio 2011.

OLIVEIRA, E.G., Educação a distância na transição paradigmática. São Paulo: Papirus, 2006. 144 p.

PALLOFF, R. M.; PRATT, K. Building online learning communities: effective strategies for the online classroom., San Francisco, CA: Jossey-Bass Publishers, 2007. $292 \mathrm{p}$.

PALLOFF, R. M.; PRATT, K. Assessing the online learner: resources and strategies for faculty. San Francisco, CA: Jossey-Bass Publishers, 2008. 153 p.

PEREIRA, J.L.C; COSTA M.P.T. O aluno com deficiência visual em sala de aula: informações gerais para professores de artes. Revista Eletrônica de Educação. São Carlos, SP: UFSCar, v.3, n.1.p.89-99, mai.2009

PEREIRA, A.T.C.; SCHMITT, V.; DIAS, M.R.A.C. Ambientes virtuais de aprendizagem. In: PEREIRA, A.T.C. (Org.). Ambientes Virtuais de Aprendizagem em Diferentes Contextos. Rio de Janeiro: Ciência Moderna, 2007. p.4-22.

TAKIMOTO, T.; BRAGA, M.M.; SCHONS, C.; GRANDO, R.K.; PEREIRA, A.T.C. Um modelo para educação a distância baseado nas estratégias de motivação das comunidades de prática. In: $9^{\mathbf{0}}$ Congresso Brasileiro de Gestão do Conhecimento, 2010, Gramado. Anais. São Paulo: Sociedade Brasileira de Gestão do Conhecimento. 2010. (CD-ROM).

TERRA, J. C.C; GORDON, C. Portais Colaborativos: A revolução na gestão do conhecimento. São Paulo: Elsevier, 2002. 453 p.

VANZIN, T. TEHCo - Modelo de ambientes hipermídia com tratamento de erros, apoiado na teoria da cognição situada, no Estado de Santa Catarina. Florianópolis: UFSC/PPGEP, 2005, 188 p. Tese de Doutorado.

WENGER, E. Communities of practice: learning, meaning, and identity. Cambridge: Cambridge University press, 1999. 318p.

WENGER, E. Communities of Practice. Learning as a social system. The Systems Thinker, Vol. 9, No. 5, June/July 1998 Disponível: http://www.co-i1.com/coil/knowledge-garden/cop/lss.shtml Acessado em: 16/05/2011

WENGER, E.; McDERMOTT, R.; SNYDER, W. Cultivating communities of practice: a guide to managing knowledge. Boston: Harvard Business School Press, 2002. 284 p. 